\title{
De la tinta a los bits (Ink to bits) Análisis de la transición de los medios impresos análogos al ambiente digital ${ }^{*}$
}

\author{
(a) \\ Juliana Castellanos Díaz \\ Recibido: 10 de diciembre de 2010 \\ Aprobado: 7 de febrero de 2011
}

\begin{abstract}
Resumen
Al concluir una década de impactantes cambios en la comunicación por cuenta del avance en el campo de la telemática, es pertinente preguntarse cuáles son las transformaciones que los periódicos más importantes de Colombia y sus países fronterizos afrontan en el terreno digital, al que debieron migrar tras las exigencias de la sociedad de la información. En consecuencia, el presente artículo de investigación examina 10 periódicos digitales a la luz de cinco categorías inherentes a la forma y fondo de los medios periodísticos en la web: multimedialidad, hipertextualidad, interactividad, instantaneidad y universalidad. El estudio permite concluir, entre otras cosas, que la escritura y las imágenes estáticas siguen constituyendo el lenguaje de los nuevos medios; los periódicos limitan las opciones de micro y macro navegación; no obstante, la interacción con el público aumenta gracias al vínculo que se genera entre éstos y los emisores a través de las redes sociales. De esta forma se evidencian cambios que implican no solo la modificación de formatos y leguajes, sino también de las estructuras mentales de quienes construyen y quienes consumen la información.
\end{abstract}

Palabras clave: prensa digital, multimedialidad, hipertextualidad, interactividad, instantaneidad, universalidad.

\footnotetext{
El proyecto de investigación del cual es producto este documento, ha sido financiado por la Fundación Universitaria Politécnico Grancolombiano, mediante el contrato de investigación No: 2010FCCACECTC28, del 14 de diciembre de 2009.

Universidad Politécnico Grancolombiano. Correo electrónico: jcastell@poli.edu.co
} 


\title{
From ink to bits. \\ Analysis of the transition from analogous printed media to digital environment
}

\begin{abstract}
At the end of a decade of strong changes in the communication field caused by the telematics progress, it is necessary to ask ourselves which are the transformations the most important newspapers in Colombia and neighbor countries face in relation to the digital world they migrate for demands made by the information society. Therefore, this research article analyzes 10 digital newspapers based on five categories concerning substance and form of the web journalistic media: multimedia, hypertext, interactivity, instantaneity, and universality. The study allows concluding, among other things, that writing and static images are still the language of new media; newspapers limit microand macro-navigation options; however, interaction with audience increases thanks to the link between audience and issuers on the social networks. In this way, changes implying not only modification of formats and languages, but also mental structures of those who construct and consume information are evident.
\end{abstract}

Key words: Digital press, multimedia, hypertext, interactivity, instantaneity, universality. 


\section{Introducción (introduction)}

Dos elementos constitutivos de la sociedad cambiaron en tan solo dos décadas, generando transformaciones profundas en las culturas de Occidente: la forma de transmisión e intercambio de datos y las maneras de interacción de los sujetos. Ambos factores consolidan un huracán tecnológico que modifica sustancialmente lo que encuentra a su paso. Ese huracán es consecuencia de la llamada era telemática.

Los cambios que se dan en el escenario de la telemática son vertiginosos, apabullantes y, sobre todo, visibles y cercanos. Eso es lo interesante, todos están involucrados cotidianamente. La red permea la esfera pública, privada e íntima de los sujetos, a tal punto que no se trata simplemente de navegarla, sino de colonizarla, porque el universo factual se hace cada vez más un estado periférico. No en vano, Mark Prensky construye la categoría nativos digitales para hacer alusión a los jóvenes que dominan perfectamente el lenguaje digital de los computadores, Internet y videojuegos (2001, citado por Cabra F. p. 324). Por equivalencia, los investigadores han optado en llamar a los que quedan fuera de la categorización como 'inmigrantes digitales', "porque han tenido que adaptarse necesariamente a ese nuevo entorno y participar en un proceso de socialización diferente" (Cabra F. 2001. p. 324).

Dadas las condiciones a las que la tecnología lleva, es propicio extender la categorización para arriesgarse a hablar de medios de comunicación nativos digitales y medios de comunicación inmigrantes digitales. Los nativos digitales son aquellos que se crean para vivir en el ámbito digital, y no han habitado, ni lo harán, en el universo analógico. Esto alude a toda la ola de periódicos, revistas, emisoras y contenidos de televisión nuevos que surgen en el escenario de la red, para convivir con todas las condiciones de esa esfera. Del otro lado están los medios que tras una experiencia y tradición física, que no abandonan, migran a la red como una forma de estar a la vanguardia. Un ejemplo contundente son los periódicos más importantes de América y Europa que llevan toda la información del impreso a una versión digital desde finales del siglo XX.

La prensa es el primer medio de comunicación que la gente vio migrar a la red. En un principio, los periodistas y editores se limitaron a presentar en el canal electrónico la información que circulaba en la versión impresa, lo que abrió la discusión sobre los cambios que debían producirse en la forma y contenido de los medios digitales. Tras las exigencias del nuevo orden los periódicos inmigrantes empezaron a modificarse, haciendo uso de las herramientas propias de la informática y la telemática así como de las teorías que alrededor del discurso ciberperiodístico empezaron a gestarse. José Álvarez Marcos, profesor de la Universidad de Sevilla, plantea que "el nuevo discurso cibernético, propio del ciberperiodismo, tiene cinco características definitorias que condicionan tanto la estructura redaccional de las informaciones como su presentación visual y gráfica" (2003, p. 243):

Multimedialidad (Multimedia). La escritura del periódico se mezcla con el sonido y la imagen en movimiento, pero también con otra cantidad de elementos inherentes a las estructuras digitales como botones y cajas de búsqueda. "Estos nuevos objetos (...) también configuran la estructura redaccional de sus informaciones y su posterior lectura" (Álvarez, 2003, p. 243).

Hipertextualidad (Hypertext). Gracias al lenguaje hipertextual los diarios cibernéticos adquieren una tercera dimensión, porque permiten una navegación en el interior del hipertexto a través de enlaces que posibilitan la ampliación de la información. Se rompe de esta manera con la linealidad de la comunicación analógica.

Interactividad (Interactivity). El proceso comunicativo que imponen los nuevos medios implica un receptor más activo que el de los medios convencionales, en tanto puede intervenir, en algunos espacios, directamente en la información con comentarios, vídeos y audios. De modo que complementa, refuta u opina sobre el relato que el sujeto emisor ha puesto en el espacio digital.

Universalidad (Universality). "En la red ningún periódico se agota y no existen más barreras y distancias que las impuestas por el ancho de banda utilizable y la calidad de los accesos"

Anagramas, Volumen 9, № 18, pp. 121-132 - ISSN 1692-2522 - enero-junio de 2011. 210 p. Medellín, Colombia 
(Álvarez, 2003, p. 243). Al fragmentarse el concepto de distancia y tiempo, la información de cualquier periódico digital del mundo se obtiene en segundos, lo que genera en muchas personas un interés por hechos distantes a su contexto inmediato.

Instantaneidad (Instantaneous). Con los nuevos medios la manera de concebir el tiempo periodístico cambia; los medios tradicionales hablaban de actualidad, pero los medios digitales dan paso a la instantaneidad. "En Internet la estricta noción de actualidad adquiere una dimensión nueva por el hecho de ser acumulativa, y no sustitutiva, acumulativa y secuencial como se materializa en los medios convencionales" (Álvarez, 2003, p. 243).

En este escenario es pertinente preguntarse hoy, tras finalizar una década de vertiginosos cambios en el campo de la comunicación, cómo se visualizan en los periódicos digitales latinoamericanos las cinco categorías planteadas. En aras de responder a la pregunta expuesta, la presente investigación se concentra en el análisis de los dos principales periódicos digitales de Colombia y de sus países fronterizos territoriales de habla hispana: Venezuela, Ecuador, Perú y Panamá. De acuerdo con la información de la Oficina de Prensa de la embajada de los países nombrados, los periódicos online más importantes corresponden a los mismos que tienen un número elevado de lectores en la versión impresa, es decir, los que en este trabajo se denominan medios inmigrantes digitales.

- Colombia: eltiempo.com, elespectador.com

- Venezuela: eluniversal.com, el-nacional.com

- Ecuador: elcomercio.com, eluniverso.com

- Perú: elcomercio.pe, larepublica.pe

- Panamá: prensa.com, pa-digital.com.pa

\section{Metodología (methodology)}

La metodología seleccionada es la propuesta por Lluís Codina, profesor de la Universidad Pompeu Fabra de Barcelona, en la obra de Ramón Salaverría y Javier Díaz Noci (2003), titulada Manual de redacción ciberperiodística.

El método permite analizar y evaluar la calidad de hiperdocumentos (sitios web, publicaciones digitales o recursos en línea). Los aspectos en los que incide son los propios de las ciencias de la documentación: 1) organización, representación y acceso a la información; 2) ergonomía; y 3) adecuación al medio digital (2003, p. 162).

Cada uno de los aspectos nombrados contiene una lista de indicadores con los que se llega a examinar las cinco características del ciberperiodismo expuestas por Álvarez Marcos. Por lo tanto, el camino propuesto desde esta investigación implica la combinación de categorías de dos importantes autores, como se presenta en la tabla 1:

\begin{tabular}{|c|c|c|}
\hline $\begin{array}{l}\text { Macroestructura } \\
\text { Ciberperiodistica }\end{array}$ & Parámetros & Indicadores \\
\hline Multimedialidad & $\begin{array}{l}\text { Adecuación al medio digital. } \\
\text { Organización, representación } \\
\text { de la información. }\end{array}$ & $\begin{array}{l}\text { Vídeos, audios, fotografías } \\
\text { Infografías. }\end{array}$ \\
\hline Hipertextualidad & $\begin{array}{l}\text { Adecuación al medio digital } \\
\text { Acceso a la información }\end{array}$ & $\begin{array}{l}\text { Secciones/nodos, Sumario/expresividad, recorrido se- } \\
\text { cuencial, navegación estructural, navegación permanente, } \\
\text { navegación semántica, recuperación de información/bús- } \\
\text { queda avanzada, enlaces externos, contexto de anclajes. }\end{array}$ \\
\hline Interactividad & $\begin{array}{l}\text { Adecuación al medio digital } \\
\text { Acceso a la información }\end{array}$ & Comunicación (receptor- emisor), redes sociales. \\
\hline Universalidad-Instantaneidad & $\begin{array}{l}\text { Adecuación al medio digital. } \\
\text { Ergonomía }\end{array}$ & $\begin{array}{l}\text { Actualización. } \\
\text { Velocidad de descarga, adaptación. }\end{array}$ \\
\hline
\end{tabular}

Fuente: elaboración propia. 


\section{Conclusiones (conclusion)}

\section{Multimedialidad (Multimedia)}

El estudio de las páginas web de los principales periódicos digitales de los países seleccionados evidencia que el lenguaje del impreso permanece con fuerza en la red, en tanto que siguen siendo la escritura y la imagen estática los elementos constitutivos de la información. Es común encontrar artículos extensos de más de 15 párrafos, acompañados por una fotografía ubicada en la parte superior de la página.

Es necesario centrar la atención en El Espectador, El Universal, El Nacional, El Comercio de Ecuador y El Panamá América; en ellos la multimedia es una sección en la que se albergan vídeos, audios, infografías y fotogalerías. Curiosa división que coloca lo multimedial como un elemento aislado, y no como una conjunción de lenguajes que deberían componer la totalidad de medio. En razón de lo expuesto, Elvira García De Torres y María José Pou proponen hablar de multimedia de convergencia y multimedia de divergencia. La primera la explican como la suma de varios formatos utilizados para comunicar; en el segundo caso explican que el producto se fragmenta para adaptarse a las necesidades de cada soporte (2003, p.72). De esta manera los periódicos nombrados se inscriben en el último escenario.

Otros periódicos como El Universo y La República presentan desde la primera interfaz un lenguaje multimedial de convergencia. En el primero, los artículos principales van acompañados de una fotogalería de tres y cuatro imágenes, que invita a una micronavegación visual que ilustra el contenido de la noticia. En el segundo caso, la página principal presenta la información más relevante a partir de una fotogalería compuesta por cinco imágenes, cada una acompañada del titular y del lead; al lado se encuentra un recuadro cuyo contenido es un vídeo y una fotografía sobre un tema relevante. Los elementos multimediales descritos son también un componente sustancial de la estética de cada sitio web, lo que confirma que en el ciberdiscurso periodístico, forma y contenido son categorías inherentes.
Lo multimedial permea la arquitectura de los periódicos digitales, trasciende del espacio de la información a la estética, de manera que lo estructural es también una conjunción de lenguajes con los que la empresa mediática traza caminos y crea nuevas experiencias entre los textos y los receptores.

En ese orden, se encuentra una similitud entre la estructura estética de los medios impresos y la prensa digital analizada. Como ocurre en los medios tradicionales, la información se ubica en un espacio que se denomina sección, nombrada en el entorno digital como nodo o lexía, y que corresponde a los tipos de fuentes periodísticas tradicionales (Política- Economía- Deportes- Judiciales- Internacionales- Locales- Tecnología).

En la web los periódicos han incluido cuatro nuevas secciones/nodos que evidencian la manera como se adecuan al entorno digital: 1) A excepción de La Prensa y El Universo, los periódicos restantes cuentan con una sección denominada Blogs. 2) El Comercio de Perú, El Comercio de Ecuador, El Universo, El Universal y El Espectador cuentan con un nodo titulado versión impresa; se suma a esta lista El Nacional, medio en el que el nodo tiene una nominación ambigua -impreso digital. 3) El Comercio de Perú, La República, Panamá América, La Prensa, El Universo y El Tiempo cuentan con un nodo titulado Archivo y ediciones anteriores. 4) Y la sección Multimedia, presentada en los párrafos anteriores.

El recorrido demuestra que la inmersión tecnológica es un proceso lento pero dinámico que va en crecimiento. "En el caso de Internet, tanto los medios como los periodistas se encuentran aún en una fase experimental en la que se aplican viejas fórmulas y se inventan otras nuevas para adaptarse a las innovaciones tecnológicas" (Alonso y Martínez, 2003, p. 265).

\section{Hipertextualidad (Hypertext)}

La manera de acceder a la información que cada nodo oferta, el tipo de datos que la componen, y la forma de escritura y de lectura que en ese espacio se permite es lo que produce un abismo entre la vieja y la nueva prensa. La suma de estas partes 
Tabla 2. Frecuencias cruzadas entre las temáticas de la pieza informativa y los diferentes de énfasis o encuadres.

\begin{tabular}{|c|c|c|c|c|c|}
\hline \multirow[b]{2}{*}{$\begin{array}{c}\text { Temática de la pieza infor- } \\
\text { mativa }\end{array}$} & \multicolumn{5}{|c|}{ Encuadre/énfasis } \\
\hline & $\begin{array}{l}\text { Ganancias- } \\
\text { Pérdidas }\end{array}$ & Interés Humano & Conflicto & $\begin{array}{c}\text { Asignación de } \\
\text { Responsabili- } \\
\text { dades }\end{array}$ & $\begin{array}{l}\text { Describir-Infor- } \\
\text { mar }\end{array}$ \\
\hline Política & 22 & 12 & 111 & 57 & 298 \\
\hline Judicial & 9 & 67 & 80 & 208 & 222 \\
\hline Economía & 185 & 17 & 3 & 8 & 99 \\
\hline Deportes & 1 & 18 & 5 & 13 & 512 \\
\hline Entretenimiento & 3 & 34 & 0 & 1 & 463 \\
\hline Internacional & 7 & 24 & 36 & 9 & 204 \\
\hline Ciencia y Tecnología & 1 & 4 & 0 & 1 & 37 \\
\hline Otros & 25 & 247 & 43 & 121 & 650 \\
\hline Total & 253 & 423 & 278 & 418 & 2485 \\
\hline
\end{tabular}

Fuente: Datos del Estudio

configura lo que se denomina hipertextualidad.

Para entrar a examinar en rigor esta categoría es necesario partir de las posibilidades de reconocimiento del espacio web que el medio suministra al receptor a través de un sumario global o un mapa general del sitio y, simultáneamente, observar si tales herramientas indican suficientemente toda la información y servicios del medio; esto se denomina dentro de la metodología seleccionada nivel de expresividad. En principio hay que reconocer que todos cuentan con un mínimo de expresividad por cuenta de la barra horizontal del inicio de la página, donde se ubican las secciones; sin embargo, esa barra no logra anunciar todos los enlaces de información e interacción que los medios contienen.

En consecuencia, los periódicos que cuentan con mayor expresividad son los colombianos y los venezolanos, a los que se suman El Comercio, de Ecuador, y La Prensa, de Panamá. Por el contrario, los periódicos de Perú carecen de una guía del sitio, lo que es reemplazado por un sumario de las secciones en la parte inferior de la página. El Universo y Panamá América son los únicos dos medios que carecen de sumarios y mapa del sitio, lo que genera altos niveles de inexpresividad entre el medio y el receptor.

La exigencia de un mapa del sitio cobra mayor sentido si se contempla el número de sec- ciones y subsecciones que presenta cada uno de los periódicos digitales estudiados .La tabla 2 permite visualizarlos:

\begin{tabular}{|l|c|c|}
\hline \multicolumn{1}{|c|}{ Periódico } & $\begin{array}{c}\text { Número de } \\
\text { secciones/nodos }\end{array}$ & $\begin{array}{c}\text { Número de } \\
\text { Subsecciones }\end{array}$ \\
\hline El Tiempo & 7 & 38 \\
\hline El Espectador & 10 & 38 \\
\hline El Universal & 17 & 31 \\
\hline El Nacional & 8 & 50 \\
\hline El Comercio (Ecuador) & 17 & 0 \\
\hline El Universo & 15 & 0 \\
\hline El Comercio ( Perú) & 10 & 0 \\
\hline La República & 22 & 0 \\
\hline La Prensa & 11 & 53 \\
\hline Panamá América & 17 & 16 \\
\hline
\end{tabular}

Fuente: Datos del Estudio

Lo anterior comprueba la cantidad de información que un medio digital puede tener, por cuenta de las posibilidades que la tecnología ofrece. No hay un límite de espacio y tiempo como ocurre en los medios análogos. Por tal razón, Codina asegura que es importante que los medios digitales le ofrezcan al receptor un recorrido secuencial: se trata de la "posibilidad de seguir el contenido de la totalidad o de una sección de 
la publicación siguiendo un recorrido secuencial o un recorrido aconsejado" (2003, p. 172). De manera explícita, solo El Tiempo recomienda recorridos al receptor, a través de las nominaciones que dio a las secciones en las que dividió la información desde octubre de 2010, fecha en la que la empresa modificó la imagen y estructura del portal; ahora el usuario, a partir de sus necesidades, elige cualquiera de los siguientes nodos: Debes saber, Debes hacer, Debes leer y Secciones (noticiosas).

Para algunos autores es el receptor el que debe tomar la decisión de las rutas a explorar en un medio digital. Javier Díaz y Ramón Salaverría se introducen en la teoría de los juegos, propuesta por el matemático John von Neumann, para explicar que en campo hipertextual:

... al igual que los participantes de un juego, los diferentes actores de una situación social deben adoptar una u otra decisión en un momento dado, lo que, si se hace mediante un plan establecido, da lugar a una estrategia (...). Del mismo modo, la recuperación de la información hipertextual se produce mediante la toma de decisiones por parte del lector que seguirá así su propio camino (2003, p. 95).

Sin embargo, no se puede olvidar que en las estructuras noticiosas clásicas se va de lo más importante a lo menos relevante, según criterio de la empresa periodística, y ello implica la estética misma de los artículos -ubicación, tamaño, luminosidad, recursos multimediales-. La puesta en escena de lo descrito termina siendo una forma de sugerir al receptor recorridos por los textos informativos.

El análisis de los recorridos sugeridos lleva a plantear un nuevo indicador, sustancial a la categoría en observación: se trata de la navegación y la facilidad que el medio brinda para tal acción. El indicador se fragmenta en dos: navegación estructural y orientación/navegación constante. El primero se refiere a la posibilidad que tiene el usuario de acceder de forma directa a cualquier sección sin necesidad de pasar por las otras. El segundo se refiere a las referencias de ubicación que le provee el medio al visitante dentro del espacio web, para que esté informado sobre la parte del sitio en el que se encuentra, así como barras de información inamovibles que lo conduzcan desde cualquier sección a la página principal, o a otras secciones.

Frente a la primera categoría, los diez periódicos digitales ofrecen una navegación estructural a partir del diseño y la ordenación del material, que incluye una o dos barras principales en las que se ubican los nodos o secciones que agrupan información por áreas temáticas. A diferencia de La República, El Universo y El Comercio de Ecuador, los otros periódicos digitales contienen subsecciones que se despliegan del nodo principal dividiendo la información en subáreas, lo que facilita la navegación por el sitio (ver tabla 2). Además, los índices, listados de titulares, recuadros y barras principales permiten un rápido acceso a los contenidos por diferentes vías, lo que evidencia una arquitectura pensada para el desplazamiento del receptor.

El segundo indicador, orientación/navegación constante, reafirma la conclusión anterior, debido a que los diez medios proveen al visitante de una herramienta de ubicación y de navegación permanente. Cuando se navega en cualquier sección de los periódicos se visualiza permanentemente la barra principal que contiene los nodos o secciones. Nunca se mueve, a menos que el nodo por el que se entre lleve a otra publicación, como ocurre con La Prensa, cuya barra principal muestra dos nodos titulados Mi Diario.com y Revistas; el primero es un enlace con otro periódico online; el segundo despliega 6 títulos de revistas que llevan a cualquiera de esas publicaciones.

Sin desconocer la importancia de los dos anteriores indicadores, es necesario decir que el siguiente es fundamental puesto que es a través de él que lo hipertextual se materializa; se trata de la navegación semántica, es decir, de las posibilidades de enlace que brinda el periodista entre los contenidos de un hiperdocumento o de diferentes hiperdocumentos. Codina establece que los enlaces se construyen por semejanza, causa/ efecto, texto/nota de aclaración, cita/referencia y explicación/ejemplo (2003, p. 175).

Es importante anotar que la navegación semántica parte de los anclajes, que son los indicios del

Anagramas, Volumen 9, No 18, pp. 121-132 - ISSN 1692-2522 - enero-junio de 2011. 210 p. Medellín, Colombia 
enlace, y se reconocen porque el periodista los presenta con un subrayado o un color diferente, con lo cual se anuncia qué parte del hiperdocumento conduce a otra orilla de información.

La investigación demuestra que la navegación semántica está reducida a una labor cosmética con la que los productores digitales hacen creer al receptor que se encuentra en una página en la que a través de la exploración de anclajes puede sumar información. No obstante, la posibilidad de navegar se reduce al paso entre los titulares, lead y fotografías (que funcionan como anclajes) a la interfaz que visualiza el artículo completo. Los periódicos que ejemplifican lo planteado son: El Nacional, El Universal, La República y El Universo. Aunque lo descrito también hace parte de esta clase de navegación, es clara la falta de aprovechamiento de la tecnología. Dicho en el inicio del artículo, los periódicos digitales siguen dando prioridad a los textos estáticos, a lo que hay que agregar la ausencia de enlaces a otras fuentes de información que dinamicen la relación entre el medio de comunicación y el receptor, y que le permitan al último ampliar el espectro de conocimientos sobre un acontecer.

Ahora bien, el objetivo de la navegación semántica se facilita con ayuda de herramientas como los tags, que a través de palabras clave tomadas del artículo noticioso le permiten al cibernauta ampliar la información, o le ayudan a encontrar temas relacionados de antiguas ediciones. A esta opción se suman los recuadros titulados Noticias relacionadas, Temas relacionados, Más información; éstas amplían las dimensiones del periódico digital y evidencian que en la era telemática no hay información que caduque, sino que, por el contrario, está siempre a la orden del día, disponible desde los enlaces que se construyen entre el nuevo y el viejo hiperdocumento. El Espectador, El Tiempo, El Comercio de Perú, La Prensa de Panamá y Panamá América, tienen siempre en todos sus artículos las herramientas señaladas. No obstante, El Comercio de Ecuador lo deja solo para los artículos de mayor relevancia. Al respecto, Codina afirma que "no todo recurso requiere esta clase de enlaces; pero se hacen más necesarios a medida que el recurso contiene más información", por lo tanto, en un medio noticioso es un recurso sustancial más que opcional.

A partir de una cierta complejidad, la navegación será insuficiente para garantizar el acceso a la información. Por muy bien resuelto que esté un sistema de navegación, es imposible, por definición, que pueda solucionar todas las clases de necesidades de información que tendrán los usuarios de esa web (Codina, 2003, p.177).

En consecuencia, las opciones de búsqueda que permiten los periódicos digitales se convierten en otra herramienta inherente a lo hipertextual. La caja de búsqueda de información se encuentra en todos los periódicos digitales estudiados; algunos contienen buscadores independientes, otros hacen uso de la tecnología de Google. En el primer caso se inscriben Panamá América, El Comercio de Ecuador, El Espectador y El Tiempo; los medios restantes responden al segundo caso.

Otra opción que ofrecen es la de búsqueda de Ediciones anteriores. La herramienta completa las opciones de navegación que un medio inmigrante debe ofrecer a sus cibernautas. El periódico La República contiene ediciones anteriores desde enero de 2004; sin embargo, cuando se intenta acceder a los primeros años del archivo digital la herramienta no da resultados. El Panamá América contiene ediciones anteriores desde el año 2000, pero al intentar descargar una publicación antigua puede tardar hasta 50 segundos. La Prensa tiene una sección denominada Archivo que guarda ediciones desde el 2000, y la búsqueda tarda entre 2 y 3 segundos. De la misma manera, en el periódico El Comercio de Ecuador la descarga de ediciones anteriores tarda entre 2 y 3 segundos, aunque las posibilidades de búsqueda se reducen a noviembre de 2009. El Universo contiene ediciones anteriores desde el 23 de marzo de 2002, y también tiene un tiempo de búsqueda de 2 segundos.

Un caso especial lo presenta El Tiempo, cuyo buscador se conecta con la sección Archivo al momento de intentar cualquier exploración; no se trata de herramientas aisladas como ocurre con los otros medios. En consecuencia, cuando el cibernauta teclea un tema particular en la caja de búsqueda, el medio no solo le ofrece la lis- 
ta de noticias relacionadas sino que el archivo arroja una línea de tiempo en la que se señalan los años que contienen mayor información sobre la temática. Este archivo es el más completo de los medios analizados debido a las posibilidades de búsqueda avanzada que ofrece a través de las siguientes categorías: palabra, sección y fecha. Además, contiene ediciones desde enero de 1911 por cuenta del registro fotográfico de las publicaciones impresas; sin embargo, la búsqueda en las primeras décadas se torna nula. Es de anotar que a diferencia de los otros periódicos, éste contiene un vídeo cuyo fin es explicar al receptor cómo ejecutar la búsqueda para obtener mejores resultados.

La exposición anterior lleva a concluir que la categoría hipertextual no es ajena a los periódicos inmigrantes sino que, por el contrario, se constituyen sobre ella en tanto que la arquitectura digital así lo implica. Sin embargo, limitar la experiencia hipertextual a la exigencia estructural reduce la explotación de las posibilidades tecnológicas, por lo que los medios estudiados se quedan en ofertar micro-navegaciones, es decir, recorridos dentro de sus páginas; con el agravante de ser, en la mayoría de casos, navegaciones cortas y circulares: del nodo a los artículos, y en sentido contrario. No obstante el paisaje puede ser más amplio, la navegación debería abrir el espectro a diferentes lugares de la información que incluso conduzcan a otras fuentes.

\section{Interactividad (Interactivity)}

Inmersos en la era telemática es necesario reconocer que la comunicación es hoy, más que nunca, un proceso simétrico en el que todas las partes son sustanciales y, por ende, ninguna más poderosa que otra. Lo que ocurre entre emisor y receptor en los periódicos digitales lo comprueba. Hoy, en un santiamén, el receptor pasa fácilmente a ser un emisor noticioso, por cuenta de la información a la que accede en contextos a los que los periodistas no llegan y que el medio le permite publicar. Además, es un receptor con voz que puede opinar sobre un tema o noticia específica al momento de terminar de leer, obviando la fila de espera y el proceso de selección al que se someten las cartas del lector en los medios impresos.

La tabla 3, construida el 28 de noviembre de 2010, expone la manera como se plantea esta posibilidad en los periódicos inmigrantes. No se puede obviar que esta tabla se puede modificar fácilmente debido a que en la red los cambios se dan en un santiamén:

\begin{tabular}{|c|c|c|c|c|c|c|}
\hline \multirow{2}{*}{ Periódicos } & \multicolumn{6}{|c|}{ Herramientas de interacción } \\
\hline & Facebook & Twitter & Carta de lectores & Blogs & Foros & Comentarios \\
\hline El Tiempo & $\begin{array}{l}57.651 \\
\text { usuarios }\end{array}$ & $\begin{array}{l}147.157 \\
\text { usuarios }\end{array}$ & $\begin{array}{l}\text { El 28/0 } 11 / 2010 \text { se encon- } \\
\text { traron } 14 \text { cartas }\end{array}$ & 547 & $\begin{array}{l}1.534 \text { partici- } \\
\text { pantes }\end{array}$ & En todas las secciones \\
\hline El Espectador & $\begin{array}{l}3.773 \\
\text { usuarios }\end{array}$ & $\begin{array}{l}51.640 \\
\text { usuarios }\end{array}$ & Permite ver dos cartas & 52 & & En todas las secciones \\
\hline La Prensa & No enlaza & $\begin{array}{l}2.523 \\
\text { usuarios }\end{array}$ & $\begin{array}{l}\text { En la sección Opinión } \\
\text { ingresan artículos que } \\
\text { los lectores envían, pero } \\
\text { el medio las selecciona. } \\
\end{array}$ & & & En todas las secciones \\
\hline Panamá América & $\begin{array}{l}625 \\
\text { usuarios }\end{array}$ & 486 usuarios & $\begin{array}{l}\text { 28/11/2010 se encontró } \\
1 \text { carta }\end{array}$ & 12 & 1.344 foros & $\begin{array}{l}\text { Yo ciudadano } \\
\text { Presenta todos los co- } \\
\text { mentarios expuestos } \\
\text { en todas las noticias. }\end{array}$ \\
\hline $\begin{array}{l}\text { El Comercio de } \\
\text { Ecuador }\end{array}$ & $\begin{array}{l}6.804 \\
\text { usuarios }\end{array}$ & $\begin{array}{l}10.245 \\
\text { usuarios }\end{array}$ & $\begin{array}{l}\text { Se pueden enviar cartas } \\
\text { al director pero no se } \\
\text { publican }\end{array}$ & 54 & $\begin{array}{l}13 \text { secciones } \\
\text { con foro. }\end{array}$ & En todas las secciones \\
\hline $\begin{array}{l}\text { El Universo de } \\
\text { Ecuador }\end{array}$ & $\begin{array}{l}57.488 \\
\text { usuarios }\end{array}$ & $\begin{array}{l}16.741 \\
\text { usuarios }\end{array}$ & $\begin{array}{l}28 / 11 / 2010 \text { se encontra- } \\
\text { ron } 7 \text { cartas }\end{array}$ & $\begin{array}{l}\text { No } \\
\text { tiene } \\
\text { blogs }\end{array}$ & $\begin{array}{l}6 \text { deja ver } \\
\text { sólo los más } \\
\text { recientes }\end{array}$ & $\begin{array}{l}\text { No permite consignar } \\
\text { comentarios }\end{array}$ \\
\hline
\end{tabular}

Anagramas, Volumen 9, № 18, pp. 121-132 - ISSN 1692-2522 - enero-junio de 2011. 210 p. Medellín, Colombia 


\begin{tabular}{|c|c|c|c|c|c|c|}
\hline $\begin{array}{l}\text { La República de } \\
\text { Perú }\end{array}$ & $\begin{array}{l}14.030 \\
\text { usuarios }\end{array}$ & $\begin{array}{l}10.380 \\
\text { usuarios }\end{array}$ & $\begin{array}{l}\text { El } 28 / 11 / 2010 \text { se encon } \\
\text { traron } 3 \text { cartas }\end{array}$ & 12 & $\begin{array}{l}\text { Sólo se mues- } \\
\text { tra el foro } \\
\text { más reciente } \\
\text { (1) }\end{array}$ & En todas las secciones \\
\hline $\begin{array}{l}\text { El Comercio de } \\
\text { Perú }\end{array}$ & $\begin{array}{l}84.973 \\
\text { usuarios }\end{array}$ & $\begin{array}{l}45.355 \\
\text { usuarios }\end{array}$ & No existe la sección & 40 & $\begin{array}{l}\text { No tiene fo- } \\
\text { ros }\end{array}$ & En todas las secciones \\
\hline $\begin{array}{l}\text { El Nacional de } \\
\text { Caracas }\end{array}$ & $\begin{array}{l}21.704 \\
\text { usuarios } \\
\end{array}$ & $\begin{array}{l}222.880 \\
\text { usuarios }\end{array}$ & No existe la sección & 16 & $\begin{array}{l}\text { No tiene fo- } \\
\text { ros }\end{array}$ & En todas las secciones \\
\hline $\begin{array}{l}\text { El Universal de } \\
\text { Caracas }\end{array}$ & $\begin{array}{l}59.390 \\
\text { usuarios }\end{array}$ & $\begin{array}{l}294.938 \\
\text { usuarios }\end{array}$ & No existe la sección & 22 & $\begin{array}{l}\text { No tiene fo- } \\
\text { ros. }\end{array}$ & $\begin{array}{l}\text { A algunas noticias se } \\
\text { les puede dejar co- } \\
\text { mentarios y a otras no }\end{array}$ \\
\hline
\end{tabular}

Fuente: Datos del Estudio

La tabla permite concluir que todos los periódicos hacen uso de herramientas web para abrirle al receptor el camino a la interacción activa y constante. Tales herramientas se reducen a dos redes sociales (Facebook y Twitter), a la tradicional opción de enviar cartas, a la posibilidad de enlazar un blog personal con el periódico, a la participación en foros con discusiones propuestas por el medio, y a los comentarios sobre los hechos y artículos que se exponen en la página. Los periódicos que hacen uso de todas las herramientas expuestas son: El Tiempo, El Panamá América y La República. Tres periódicos de la decena de analizados es una cifra baja que pone en el centro del debate la urgencia de implementar otras opciones de interacción para los usuarios, no solo en los periódicos que no cuentan con alguna de las opciones presentadas sino para la totalidad de medios que se encuentran aún en estado de exploración de nuevas formas de interactividad.

Es importante resaltar que la totalidad de periódicos en observación están suscritos a Twitter y Facebook, ninguno hace parte de otra red social; la mayoría de ellos exponen los iconos de estas redes en la página de inicio, convirtiéndose en anclajes que permiten enlazarse a sus cuentas. En este caso llama la atención El Espectador que, a pesar de pertenecer a ambas redes, no expone los enlaces desde su página principal, por lo que el receptor debe tomarse tiempo y buscarlos en la web. Un segundo caso es el de La Prensa, que expone en su página los enlaces a las dos redes pero solo la de Twitter es funcional.

La sección Carta de los Lectores impacta por dos razones: primera, porque no es común en todos los diarios, muestra de ello son La Repú- blica, El Nacional y El Universal que carecen de la tradicional opción de comunicación; segunda, porque no todos los medios las publican, como ocurre en El Comercio de Ecuador donde la sección recibe el nombre de Cartas al Director, pero no hay lugar a la publicación de los mensajes que se envían. No obstante, el periódico que más cartas expone en su página es El Tiempo, con 14 mensajes (29 de noviembre de 2010).

El periódico La Prensa presenta otra experiencia de interactividad. No tiene una sección similar a las que se vienen comentando, pero da la opción a los receptores de enviar artículos de opinión que son previamente aprobados para su publicación.

Los blogs son otra interesante herramienta de la que se valen los periódicos para abrir espacios de participación. La tarea de los medios es admitirlos y permitir su enlace desde la página principal o a través de una sección consolidada para ellos. Es en el periódico El Tiempo donde la opción resalta por el número de blogs admitidos; el 25 de noviembre de 2010 sumaban 547. A diferencia de las otras herramientas de interacción, los blogs no son, necesariamente, respuestas de los receptores a los aconteceres o a la información, sino que están ligados a la profesión, aficiones, gustos, entre otras cosas, de los bloggers.

Los foros son utilizados por cinco periódicos para invitar a la discusión sobre temas importantes de la agenda mediática. Se redactan en forma de pregunta en aras de invitar a los receptores a plantear su opinión en formato de respuesta. De esta herramienta carecen El Nacional, El Universal, El Espectador, La Prensa y el Comercio de Perú. 
Una opción de interactividad común, y una de las más antiguas desde la aparición de los medios digitales, es el comentario a una noticia. Los receptores pueden exponer su opinión o sus conocimientos sobre un acontecer o sobre la manera como fue tratado por el medio, incluso, sobre el comentario de otro receptor. Solo uno de los periódicos estudiados no brinda está opción a sus visitantes: se trata de El Universo de Ecuador. Aunque el medio cuenta con otras posibilidades de interacción, desequilibra la balanza de la comunicación dando más poder a los emisores.

La suma de las herramientas presentadas constituye el camino que los diferentes medios emprendieron una década atrás:

La interactividad es uno de los elementos que de manera más sobresaliente configura lo que hemos identificado como comunicación digital. Constituye la facultad de la tecnología digital de que un usuario pueda preguntar al sistema o entorno mediático que tiene frente a él, y que éste le responda. La interactividad puede entenderse, entonces, como un proceso de comunicación, de intercambio, de diálogo si cabe" (Alonso y Martínez, 2003, p. 281).

\section{Universalidad e instantaneidad (Universality and Instantaneous)}

Con Internet los periódicos inmigrantes dejan de pertenecer a contextos limitados, debido a que pasan de un público nacional a uno internacional. Lo anterior debería repercutir en los contenidos, estéticas y ergonomía del medio; no obstante, las secciones, temas y lenguajes siguen siendo locales. En consecuencia, la universalidad se reduce a una cuestión técnica que implica la posibilidad de acceder a la página web en cualquier espacio del orbe, y se deja de lado que la categoría también impone un nuevo sentido a la información que debería ir de lo nacional a lo global sin caer en extremos nocivos.

De los diez periódicos estudiados solo uno evidencia que la universalidad supera lo técnico. Se trata de La Prensa de Panamá, que ofrece 52 idiomas para que el lector adapte la información al suyo. La posibilidad se da a través del traductor de Google, que luego de que alguien selecciona un idioma instantáneamente traduce toda la información expuesta en el medio. De esta manera el periódico crea una proximidad con el público internacional, pese a que el contenido sigue teniendo límites locales.

Ahora bien, el estudio anterior sobre la interactividad también hace parte de la universalidad porque abre la posibilidad de comunicación entre el medio y el receptor de cualquier lugar del mundo. Las redes sociales, los espacios para opinar, las cartas del lector, y las opciones de colgar vídeos y audios no se limitan a los públicos nacionales sino que abre las puertas al intercambio de información con receptores extranjeros.

En el escenario de la producción mediática la instantaneidad se suma a la universalidad, debido a que la información solo tarda en llegar fracciones de segundos. De manera simultánea a un hecho noticioso, la información se coloca en la página de los periódicos en formato de vídeo, audio o texto. La facilidad de la herramienta supera las condiciones técnicas y temporales del periódico impreso, que tarda horas en publicar una edición. Por el contrario, en el digital la información está al instante, a lo que se suma la oportunidad de actualizarla a medida que se van generando nuevos datos, constituyendo así un medio de noticias abiertas que se nutren con el correo del día. En consecuencia, la actualización es cada vez más frecuente en los medios observados, por lo que los receptores se acostumbran también a encontrar frente a cada noticia la hora en la que fue actualizada, lo que permite mayores estándares de exigencia.

Los resultados de la investigación evidencian el desarrollo de una nueva prensa que pese a ser inmigrante hace un importante esfuerzo por transformar su lenguaje, sus ritmos de producción, sus lógicas de construcción de información, la manera de visualizarse y consumirse, y por lo tanto, su manera de relacionarse con los receptores. Las modificaciones, más fuertes en unas esferas que en otras de las cinco estudiadas, se van dando con las dificultades que todo cambio conlleva, sobre todo si se considera que no se 
trata únicamente de transformar los formatos sino también las estructuras mentales que acompañaron por más de un siglo tanto a los productores de la información como a los receptores de la misma. Es innegable, entonces, que la sociedad latinoamericana acude a una mediamorfosis, como lo llamo Roger Fidler (1998), que aún no concluye porque el camino es largo, sorpresivo, y, sobre todo, mutable. En consecuencia, es claro que queda mucho por investigar de este terreno que se torna cada día más amplio y, por ende, más complejo.

\section{Referencias bibliográficas}

Alonso Jaime y Martínez Lourdes (2003). Medios interactivos: caracterización y Contenidos. En: Manual de redacción Ciberperiodística. Javier Díaz Noci, Ramóna Salaverría (coords.).España: Ariel Comunicación.

Álvarez Marcos J. (2003). El Periodismo ante la tecnología hipertextual. En: Manual de redacción ciberperiodística. Javier Díaz Noci, Ramóna Salaverría (coords). España: Ariel Comunicación.

Cabra Fabiola; Marciales Gloria (2009). Mitos, Realidades $\&$ Preguntas de Investigación sobre los 'Nativos
Digitales'. En: Universitas Psychologica. Vol 8. N0 2. Mayo- Agosto.

Codina Lluis (2003). "Hiperdocumentos: Composición, Estructura y Evaluación". En: Manual de redacción ciberperiodística. Javier Díaz Noci, Ramón Salaverría (coords).España: Ariel Comunicación.

Flores Jesús \& Arruti Alberto Miguel (2001). Ciberperiodismo. Nuevos enfoques, conceptos y profesiones en el mundo infodigital. Madrid. Limusa Noriega Editores.

García de Torres Elvira y Pou Amérigo María José, (2003). "Características de la Comunicación Digital". En: Manual de redacción ciberperiodística. Javier Díaz Noci, Ramóna Salaverría (coords).España: Ariel Comunicación.

López, Hidalgo (2009). Géneros periodísticos complementarios. una aproximación crítica a los formatos del periodismo visual. Sevilla: Alfaomega.

Pena de Oliveira Felipe (2009). Teoría del Periodismo. México: Alfaomega.

Salavarría Ramón, Díaz Javier (2003). Manual de redacción ciberperiodística. España: Ariel Comunicación. 